\title{
Sabot Concept Evaluation Using Subscale Airgun-Launched 3-D Printed Components
}

\author{
by Ilmars Celmins
}

ARL-TR-7187

February 2015 


\section{NOTICES}

\section{Disclaimers}

The findings in this report are not to be construed as an official Department of the Army position unless so designated by other authorized documents.

Citation of manufacturer's or trade names does not constitute an official endorsement or approval of the use thereof.

Destroy this report when it is no longer needed. Do not return it to the originator. 


\title{
Army Research Laboratory
}

Aberdeen Proving Ground, MD 21005-5066

\section{Sabot Concept Evaluation Using Subscale Airgun-Launched 3-D Printed Components}

\author{
Ilmars Celmins \\ Weapons and Materials Research Directorate, ARL
}




\section{REPORT DOCUMENTATION PAGE}

Form Approved OMB No. 0704-0188

Public reporting burden for this collection of information is estimated to average 1 hour per response, including the time for reviewing instructions, searching existing data sources, gathering and maintaining the data needed, and completing and reviewing the collection information. Send comments regarding this burden estimate or any other aspect of this collection of information, including suggestions for reducing the burden, to Department of Defense, Washington Headquarters Services, Directorate for Information Operations and Reports (0704-0188), 1215 Jefferson Davis Highway, Suite 1204, Arlington, VA 22202-4302. Respondents should be aware that notwithstanding any other provision of law, no person shall be subject to any penalty for failing to comply with a collection of information if it does not display a currently valid OMB control number.

PLEASE DO NOT RETURN YOUR FORM TO THE ABOVE ADDRESS.

\begin{tabular}{|c|c|c|}
\hline $\begin{array}{l}\text { 1. REPORT DATE (DD-MM-YYYY) } \\
\text { February } 2015\end{array}$ & $\begin{array}{l}\text { 2. REPORT TYPE } \\
\text { Final }\end{array}$ & $\begin{array}{l}\text { 3. DATES COVERED (From - To) } \\
\text { August 2011-October } 2013\end{array}$ \\
\hline \multirow{4}{*}{\multicolumn{2}{|c|}{$\begin{array}{l}\text { 4. TITLE AND SUBTITLE } \\
\text { Sabot Concept Evaluation Using Subscale Airgun-Launched 3-D Printed } \\
\text { Components }\end{array}$}} & 5a. CONTRACT NUMBER \\
\hline & & \\
\hline & & 5b. GRANT NUMBER \\
\hline & & 5c. PROGRAM ELEMENT NUMBER \\
\hline \multirow{3}{*}{\multicolumn{2}{|c|}{ 6. AUTHOR(S) }} & $\begin{array}{l}\text { 5d. PROJECT NUMBER } \\
\text { AH80 }\end{array}$ \\
\hline & & 5e. TASK NUMBER \\
\hline & & 5f. WORK UNIT NUMBER \\
\hline \multicolumn{2}{|c|}{$\begin{array}{l}\text { 7. PERFORMING ORGANIZATION NAME(S) AND ADDRESS(ES) } \\
\text { US Army Research Laboratory } \\
\text { ATTN: RDRL-WML-E } \\
\text { Aberdeen Proving Ground, MD 21005-5066 }\end{array}$} & $\begin{array}{l}\text { 8. PERFORMING ORGANIZATION } \\
\text { REPORT NUMBER } \\
\text { ARL-TR-7187 }\end{array}$ \\
\hline \multirow{2}{*}{\multicolumn{2}{|c|}{ 9. SPONSORING/MONITORING AGENCY NAME(S) AND ADDRESS(ES) }} & 10. SPONSOR/MONITOR'S ACRONYM(S) \\
\hline & & $\begin{array}{l}\text { 11. SPONSOR/MONITOR'S REPORT } \\
\text { NUMBER(S) }\end{array}$ \\
\hline
\end{tabular}

12. DISTRIBUTIONIAVAILABILITY STATEMENT

Approved for public release; distribution is unlimited.

13. SUPPLEMENTARY NOTES

\section{ABSTRACT}

A recent gun launch experimental program required that the pusher assembly of the launch package be diverted so that it would not follow behind the projectile being evaluated. Initial experiments showed that a subscale launch package fired from a 2-inch (51-mm)-diameter air gun exhibited similar sabot discard performance to the full-size projectile. The subscale launch package was assembled from parts built from plastic via rapid prototyping (3-dimensional printing). Subsequent evaluation of several sabot concepts revealed that the best design had one of the 4 sabot petals firmly attached to the pusher assembly so that the discarding sabot petal pulled the pusher assembly off of the line of fire. The modified assembly was fabricated and fired from the full-scale 8-inch (203-mm) gun. Sabot discard and pusher diversion occurred as expected, allowing the experimental program to proceed. The launch package modifications are described, and a simple analysis of basic equations of force and motion illustrates why a low-speed, subscale simulation can be used for first order evaluations of sabot discard phenomena.

15. SUBJECT TERMS

sabot, sabot discard, stripper, subscale, airgun, 3-D printing

\begin{tabular}{|l|l|l|c|c|l|}
\hline \multicolumn{2}{|l|}{ 16. SECURITY CLASSIFICATION OF: } & $\begin{array}{l}\text { 17. LIMITATION } \\
\text { OF ABSTRACT }\end{array}$ & $\begin{array}{l}\text { 18. NUMBER } \\
\text { OF PAGES }\end{array}$ & $\begin{array}{l}\text { 19a. NAME OF RESPONSIBLE PERSON } \\
\text { Ilmars Celmins }\end{array}$ \\
\cline { 1 - 2 } $\begin{array}{l}\text { a. REPORT } \\
\text { Unclassified }\end{array}$ & $\begin{array}{l}\text { b. ABSTRACT } \\
\text { Unclassified }\end{array}$ & $\begin{array}{l}\text { c. THIS PAGE } \\
\text { Unclassified }\end{array}$ & UU & 20 & $\begin{array}{l}\text { 19b. TELEPHONE NUMBER (Include area code) } \\
410-306-0781\end{array}$ \\
\hline
\end{tabular}




\section{Contents}

List of Figures $\quad$ iv

$\begin{array}{lr}\text { 1. Introduction } & 1\end{array}$

2. Description of the Sabot Discard Problem 1

2.1 Very Affordable Precision Projectile ...................................................................1

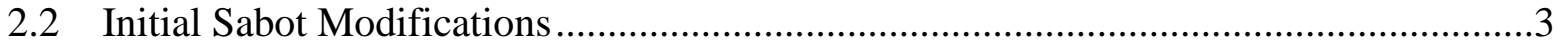

3. Subscale Airgun Testing $\quad 4$

3.1 US Army Research Laboratory (ARL) Airgun ....................................................4

3.2 Subscale Models...........................................................................................

3.3 Subscale Airgun Experimental Results .................................................................5

3.4 Full-Scale Confirmation ........................................................................................

4. Why It Works $\quad 10$

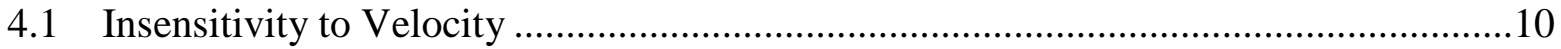

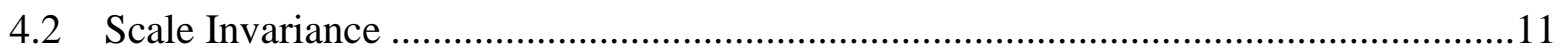

5. Conclusions $\quad 12$

$\begin{array}{ll}\text { 6. } & \text { References }\end{array}$

$\begin{array}{ll}\text { Distribution List } & 15\end{array}$ 


\section{List of Figures}

Fig. 1 Photograph of VAPP projectiles with and without canards; solid model of VAPP projectile and sabot assembly...

Fig. 2 Sabot stripper plate at the TEF spark shadowgraph range entrance ..................................3

Fig. 3 Half-moon pusher disk cutout resulting in large projectile yaw ...................................4

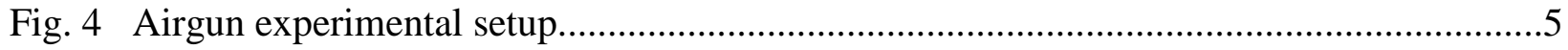

Fig. 5 Baseline sabot and pusher configuration, full scale and subscale ................................6

Fig. 6 Half-moon pusher configuration, full scale and subscale...........................................6

Fig. 7 High-speed video of airgun launch of attached sabot concept ......................................

Fig. 8 Modified projectile assembly and pusher assembly with stripper pole............................8

Fig. 9 Modified projectile assembly with one sabot petal affixed to pusher ..............................9

Fig. 10 Flight follower video of attached-sabot concept, fired from 8-inch gun.......................10 


\section{Introduction}

The characterization of sabot discard is an important issue in many ammunition development programs and also in experimental programs. The current discussion is geared more toward the experimental issues but is applicable to both.

Sabots are often designed as an adjunct to a flight experiment. The sabot is a required tool that is needed to launch a projectile to gather some type of in-flight data or terminal effects performance. Since sabot development is a parasitic cost to the experimental program, it is always desired to expend the minimal amount of resources on the design, evaluation, and refinement of the sabot system. However, having a consistently well-performing sabot package is often of crucial importance to the success of the flight experiment.

This report describes the successful use of a 2-inch, low-velocity airgun to simulate the sabot discard of an 8-inch-diameter powder gun. Comparative results are presented, followed by a simple derivation of the physics explaining why the technique is successful.

\section{Description of the Sabot Discard Problem}

\subsection{Very Affordable Precision Projectile}

There was a requirement to fire the Very Affordable Precision Projectile (VAPP) ${ }^{1}$ through the Transonic Experimental Facility (TEF) spark shadowgraph range. The VAPP had been previously fired for flight characterization. Although the VAPP was designed to be launched from a 105-mm gun tube with deployable tail fins, the initial flight experiment projectiles had fixed tail fins because the deployable fin design was not yet mature. The fixed tail fin VAPP was fired from an 8-inch (203-mm) smoothbore gun using sabots.

The projectile and sabot is shown in Fig. 1. The sabot assembly consisted of 4 main sabot petals, which rested on a set of 6 wedges that fit between the projectile fin blades. A pusher assembly at the rear of the launch package provided obturation and transmitted the acceleration load to the projectile and sabots. The pusher disk consisted of a nylon disk with an aluminum plate on top. 

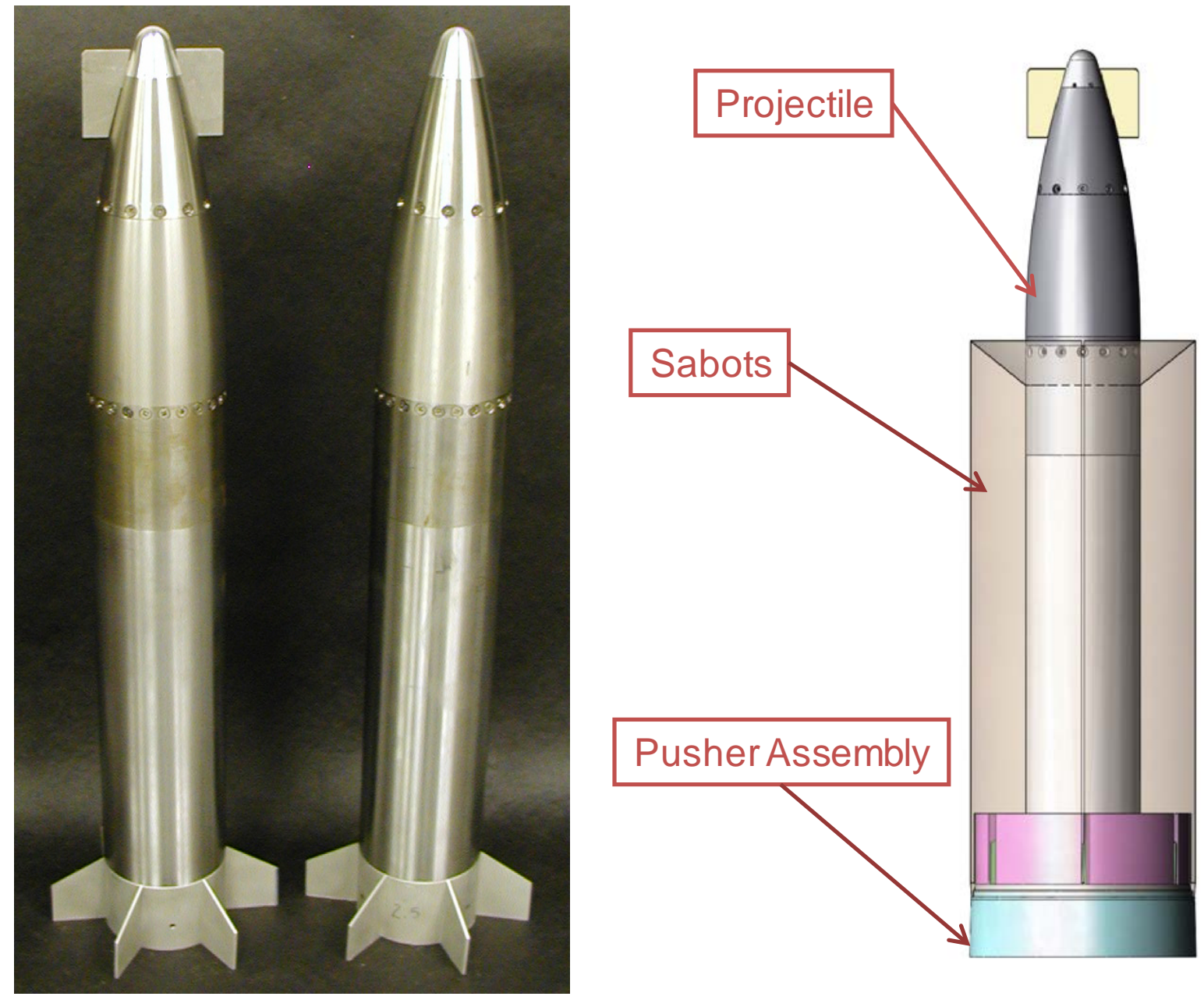

Fig. 1 Photograph of VAPP projectiles with and without canards; solid model of VAPP projectile and sabot assembly.

The sabot design worked well for its intended purpose (launching the projectile into free flight). However, it was not suitable for firing through the TEF spark range due to the pusher. The pusher tends to follow directly behind the projectile through the early portion of the flight. The entrance to the spark range has a stripper plate (shown in Fig. 2) with a nominally 46-cm-diameter hole, located approximately $25 \mathrm{~m}$ from the gun muzzle.

Preliminary launch experiments with yaw cards showed that the pusher plate would have consistently followed the projectile through the stripper plate hole. This was unacceptable in that the pusher plate would be likely to damage and destroy instrumentation if it were to enter the spark shadowgraph facility. 


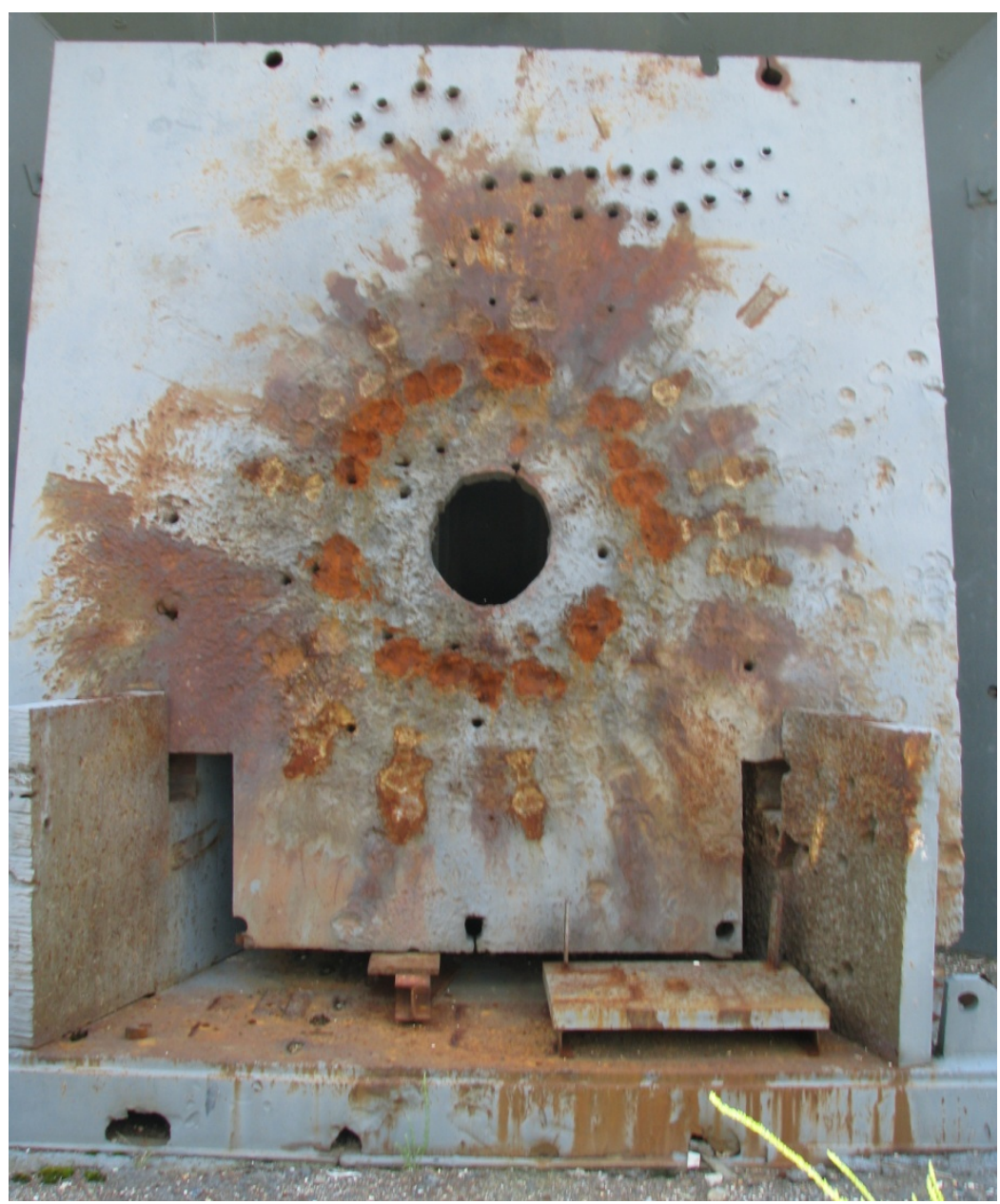

Fig. 2 Sabot stripper plate at the TEF spark shadowgraph range entrance

\subsection{Initial Sabot Modifications}

It was initially decided to try several simple modifications to the existing sabots and test them, since it was hoped to avoid a full-blown sabot redesign effort and the subscale method described in this report had not yet been developed. The first of these modifications was to tie one of the sabot petals to the pusher plate using rope and eyebolts. The hope was that the sabot petal would drag the pusher with it as it discarded. This failed primarily because the rope/eyebolt combination was not strong enough. Either the rope broke or the eyebolts bent as the sabot petal pivoted away from the pusher.

A second attempt involved modifying the pusher plate by cutting out a section of the base. The theory here was that asymmetric muzzle blast loading would deflect the pusher disk and then aerodynamic forces would push it to the side. Although this technique did deflect the pusher to some extent, it also induced a large amount of yaw to the projectile as shown in Fig. 3. 


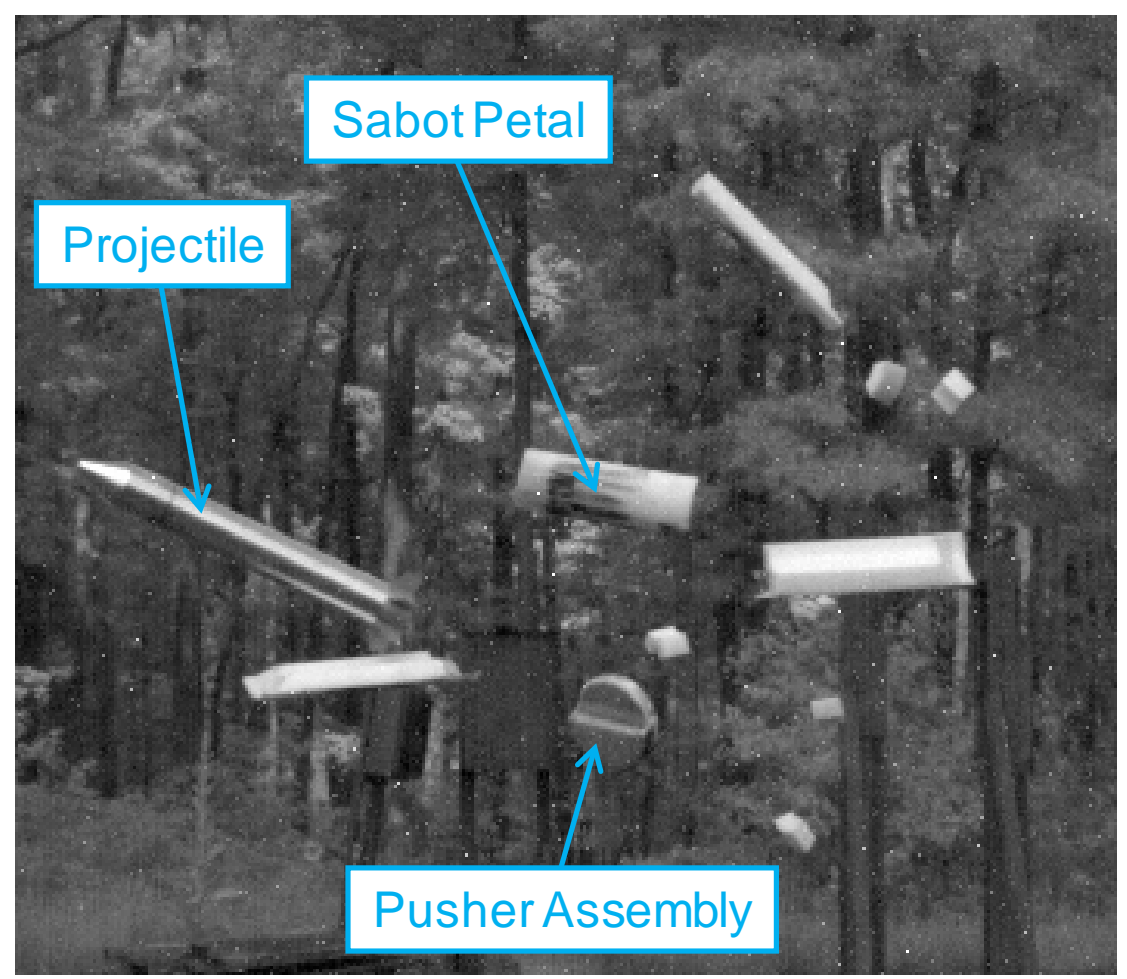

Fig. 3 Half-moon pusher disk cutout resulting in large projectile yaw

At this point the full-scale cut and try method was abandoned due to the costs of fabricating hardware and performing large-caliber flight experiments.

\section{Subscale Airgun Testing}

\subsection{US Army Research Laboratory (ARL) Airgun}

ARL has an airgun (or soft-launch system) that has been previously used for simple flight experiments of various aerodynamic configurations and for evaluating onboard instrumentation. The system can accommodate different barrel diameters. Standard available nominal gun tube internal diameters are 2, 3, and 4 inches (51, 76, and $102 \mathrm{~mm}$ ).

It was decided to use the 2-inch (51-mm) tube to provide quick, inexpensive data for a variety of sabot stripping concepts. This meant the parts were small and could be produced quickly and inexpensively via rapid prototyping processes (3-dimensional [3-D] printing).

The nominal launch velocity was $75 \mathrm{~m} / \mathrm{s}$, compared with $300 \mathrm{~m} / \mathrm{s}$ for the full-scale shots. The airgun experimental setup is shown in Fig. 4. 


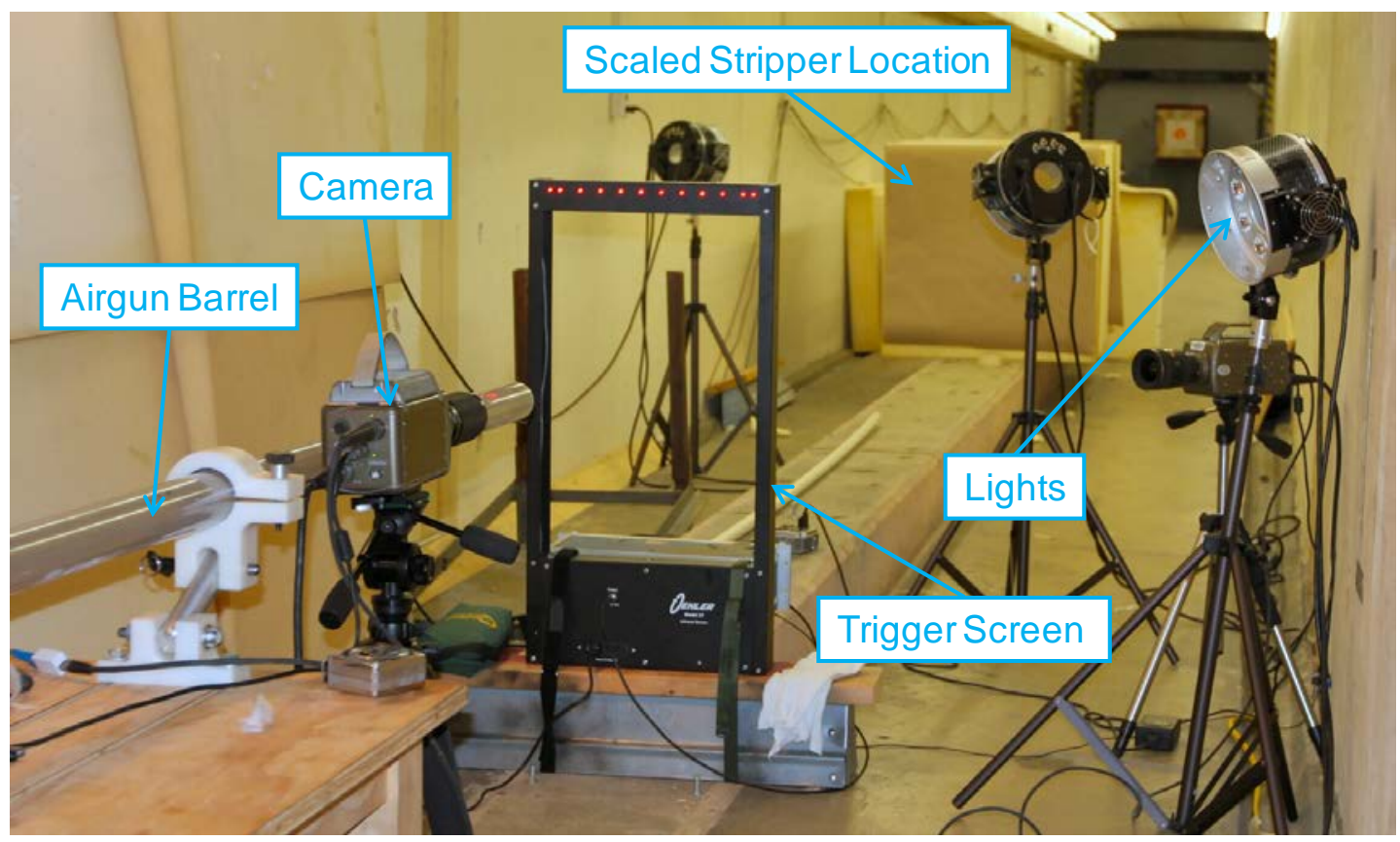

Fig. 4 Airgun experimental setup

\subsection{Subscale Models}

The subscale projectile and sabot parts were fabricated by the Rapid Technologies and Inspection Branch of the Advanced Design and Manufacturing Division of the Edgewood Chemical Biological Center, located at the Edgewood Area of Aberdeen Proving Ground, using the selective laser sintering process on a 3-D Systems Sinterstation 2500 plus with Advanced Laser Materials PA nylon material. This process and material produces parts that have properties similar to the nylon used to make the full-size sabots.

The subscale projectile was also fabricated from the same material as the subscale sabots. This meant that the subscale projectile was less dense than the full-scale version (approximately 40\% of the density), which would make it relatively more sensitive to launch disturbances. This was deemed to be acceptable for 2 reasons. First, the main focus was to find a way to strip off the pusher disk, and second, having a more sensitive projectile in the subscale experiments would provide a clearer indication of potential projectile launch disturbances.

\subsection{Subscale Airgun Experimental Results}

The initial subscale launch experiments replicated the full-scale tests so that the suitability of the experimental technique could be validated. Figures 5 and 6 show comparisons of full scale and subscale firings for the baseline sabot configuration and the half-moon pusher cutout configuration. The images are frames from high-speed videos of the flight experiments. The similarity of the results was encouraging. There were more significant differences for the halfmoon pusher firings, but this is to be expected because this concept relies on muzzle blast to provide the asymmetry. The muzzle blast from an air gun and powder gun will be quite different. 


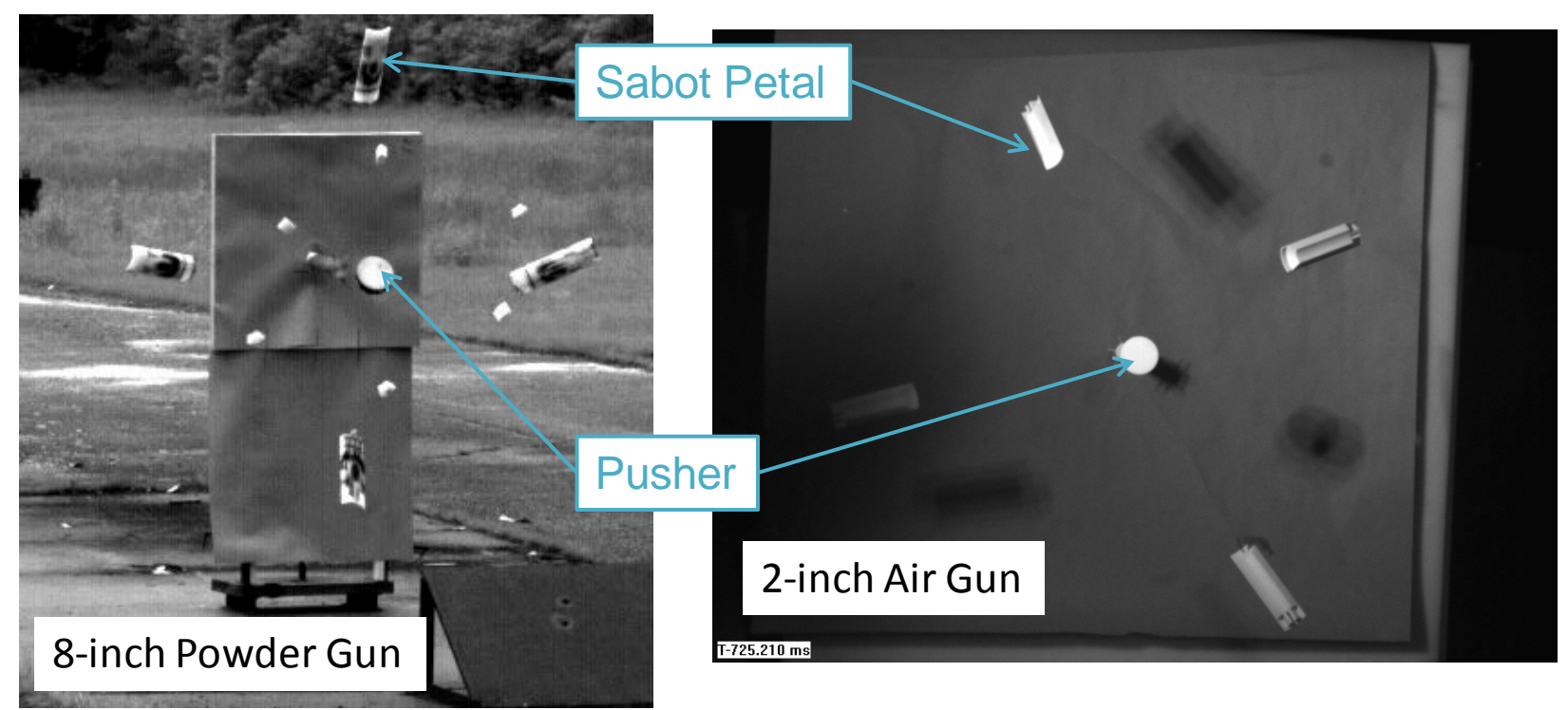

Fig. 5 Baseline sabot and pusher configuration, full scale and subscale

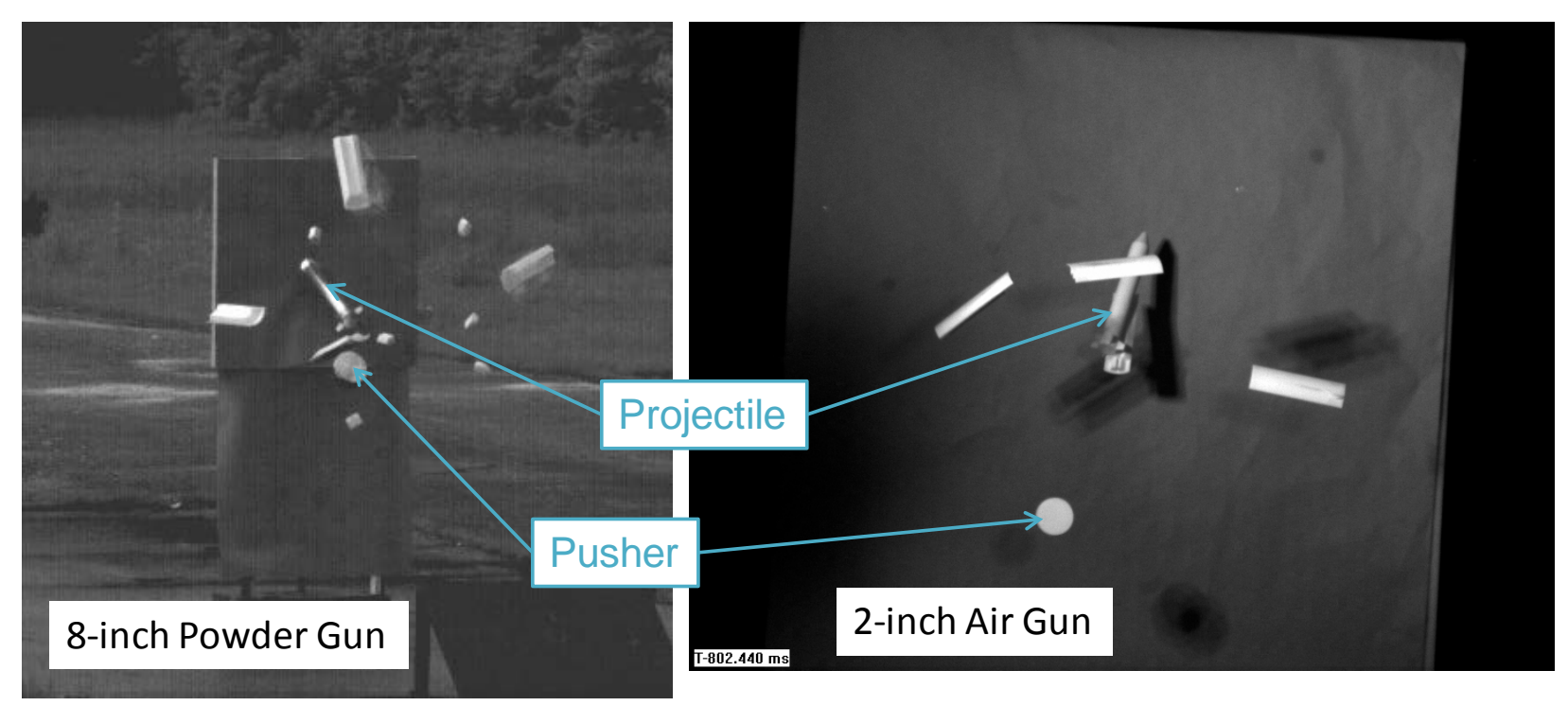

Fig. 6 Half-moon pusher configuration, full scale and subscale

Subsequent subscale launch experiments were then conducted on several different stripper concepts, with varying degrees of success. The most promising concept had one of the sabot petals firmly attached to the pusher assembly, so that the sabot petal dragged the pusher off of the line of fire. Figure 7 is a high-speed video showing an air gun launch of this concept. The camera is positioned to the side of the gun muzzle, looking downrange. A paper-covered foam block is positioned at the scaled distance of the TEF stripper plate. 


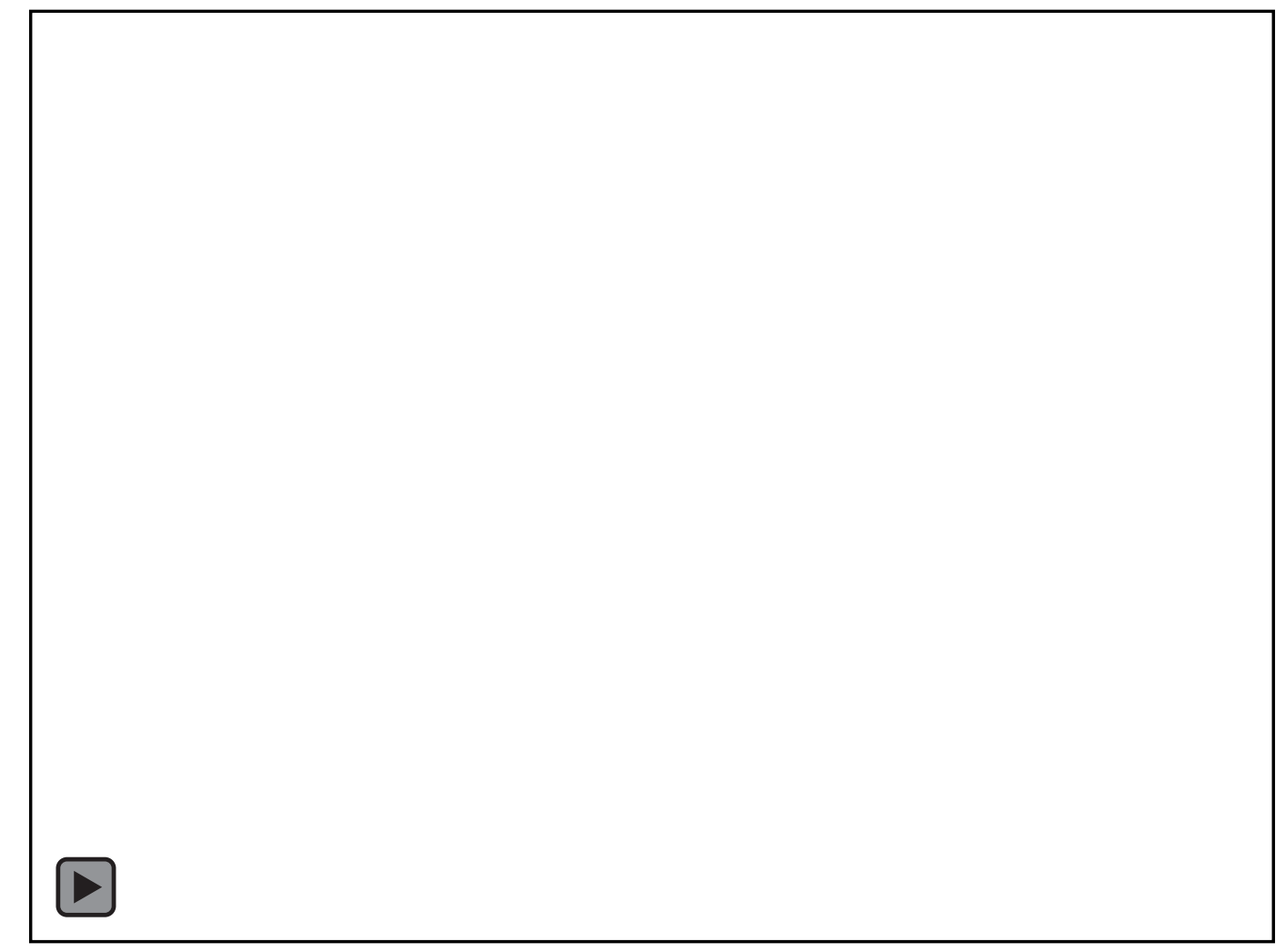

Fig. 7 High-speed video of airgun launch of attached sabot concept

\subsection{Full-Scale Confirmation}

The most promising design concept from the subscale experiments was applied to the full-scale sabot assembly. One of the sabot petals was rigidly attached to the pusher by bolting an aluminum rod (stripper pole) to the pusher, having the rod mate with a hole drilled in the sabot petal. Figure 8 shows a photograph and solid model of the modified projectile assembly.

This modified full-scale assembly was fabricated and fired from the 8-inch gun. Sabot discard pictures from both the subscale and full-scale flight experiments are shown in Fig. 9. The results were again consistent and the full-scale results showed that the pusher plate was being pulled off of the line of fire far enough that it would consistently impact the stripper plate, thereby preventing it from entering the spark range. 


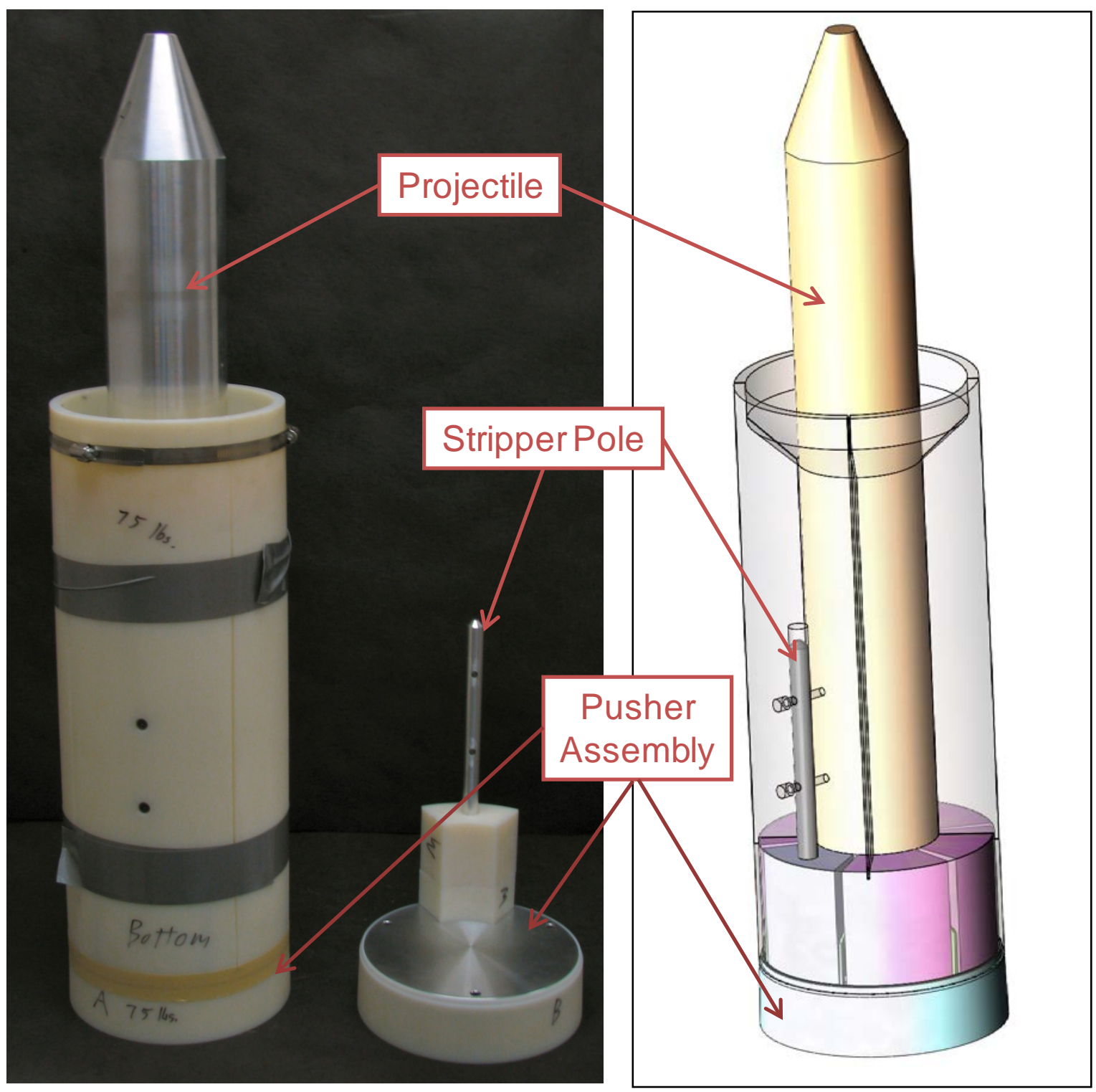

Fig. 8 Modified projectile assembly and pusher assembly with stripper pole 


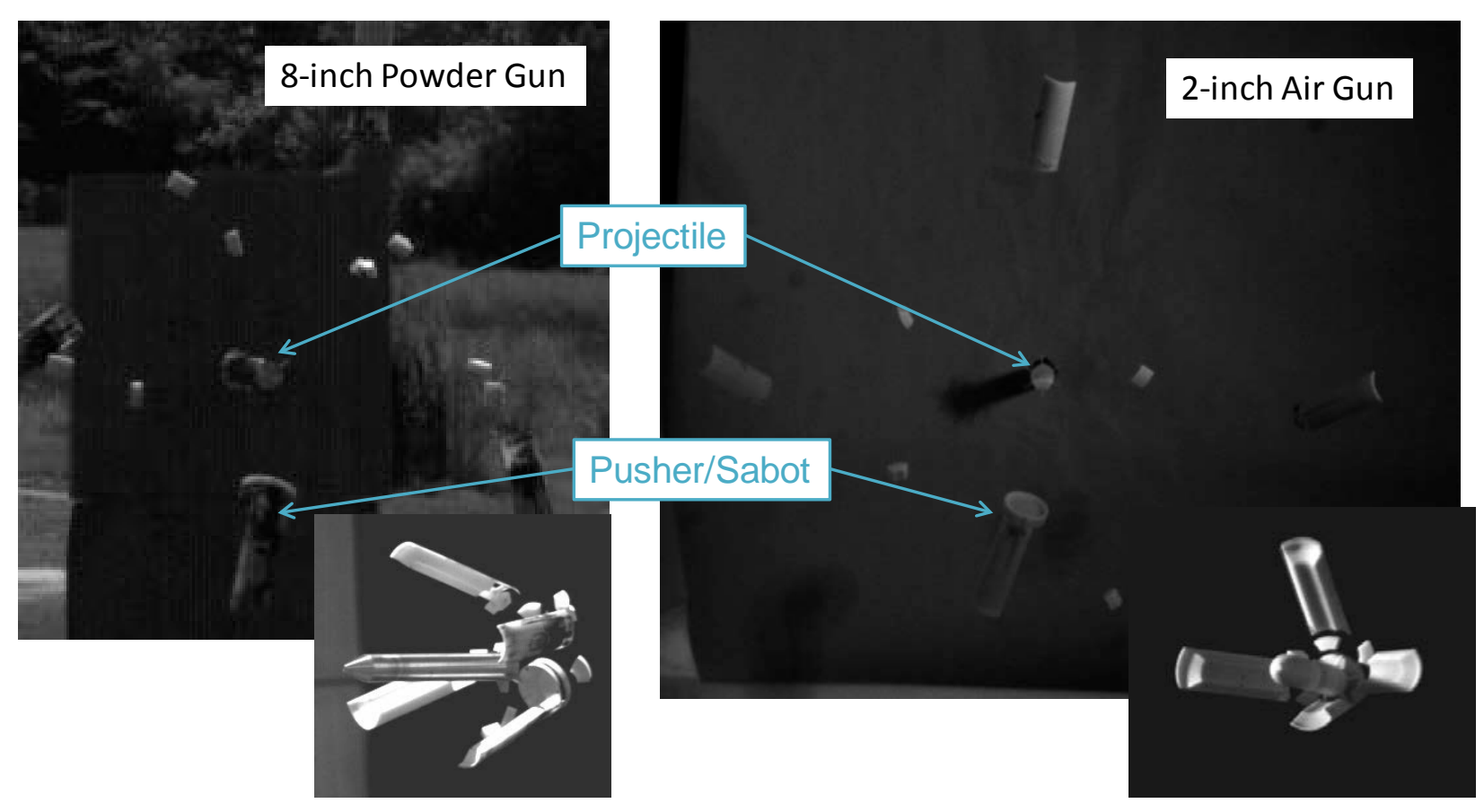

Fig. 9 Modified projectile assembly with one sabot petal affixed to pusher

This configuration was then successfully used to fire data shots through the spark range (the original goal of this project). Figure 10 is a movie from a flight follower camera showing the effectiveness of the attached-sabot concept when fired from the 8-inch powder gun. The video clearly shows the sabot petal pulling the pusher down and away from the line of fire. The yaw card that appears near the end of the video is located at the same distance from the muzzle as the stripper plate when firing through the TEF. 


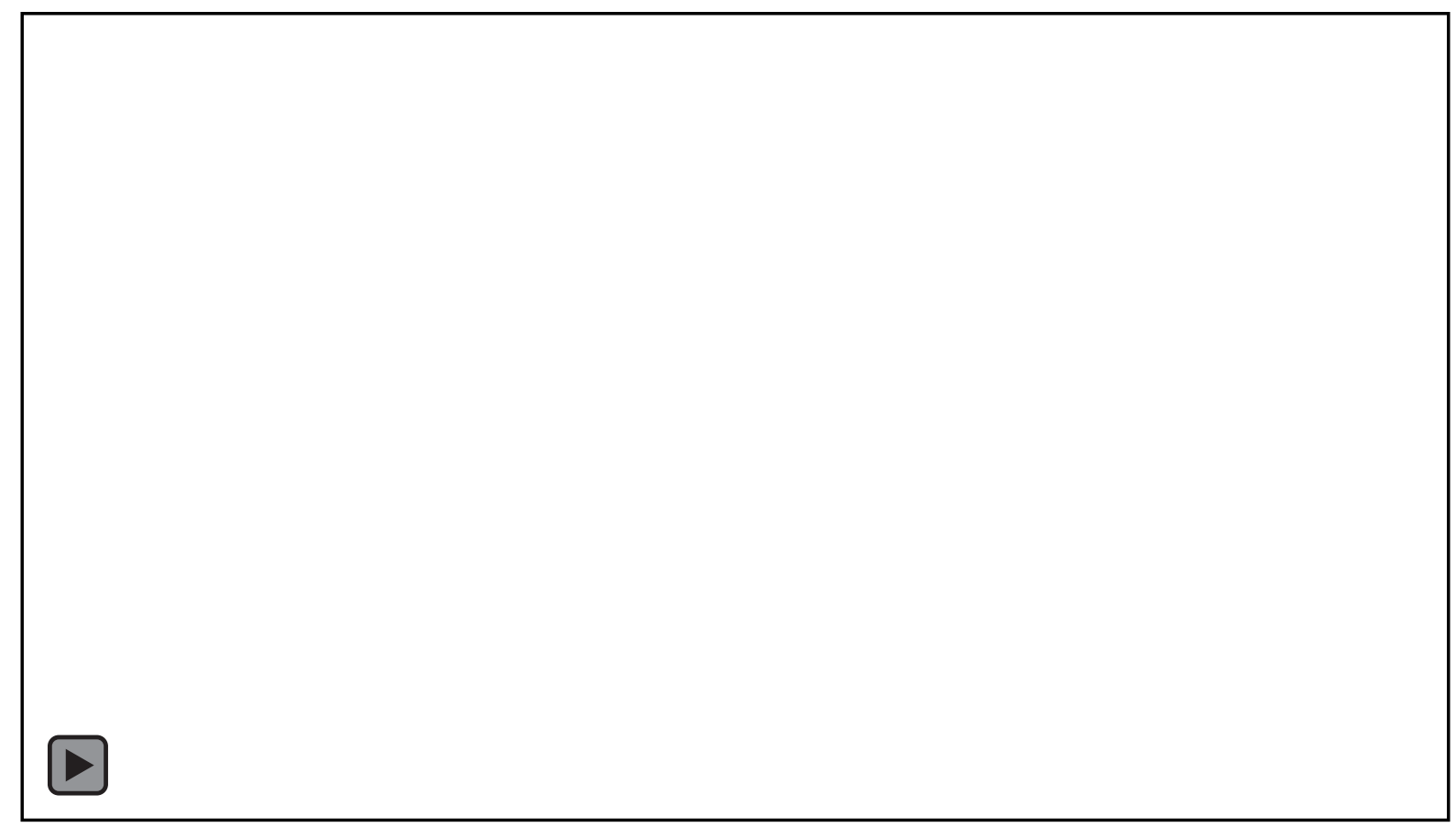

Fig. 10 Flight follower video of attached-sabot concept, fired from 8-inch gun

\section{Why It Works}

It is not immediately or intuitively obvious why a lower speed, 1/4-scale air gun launch experiment of sabot separation would match the results seen in a full-scale powder gun firing. However, a quick examination of some basic equations of force and motion clarifies why this is so.

\subsection{Insensitivity to Velocity}

The effect of launch velocity on sabot discard will be explored first. For a nonspinning projectile, the primary force that drives sabot discard is the result of air pressure on the sabot petal. This force is defined as

$$
\mathrm{F}=\mathrm{PA} \text {, }
$$

where $\mathrm{F}$ is force, $\mathrm{P}$ is pressure, and $\mathrm{A}$ is the net effective area over which the pressure is acting. The pressure, $\mathrm{P}$, is the dynamic air pressure, which is defined as

$$
\mathrm{P}=1 / 2 \rho \mathrm{V}^{2}
$$

where $\rho$ is the air density and $\mathrm{V}$ is the sabot velocity.

The resultant acceleration, a, of a sabot petal with a mass of $\mathrm{m}$ is simply 


$$
\mathrm{a}=\mathrm{F} / \mathrm{m} \text {. }
$$

The flight time, t, from the gun muzzle to the stripper plate can be approximated by

$$
\mathrm{t}=\mathrm{x} / \mathrm{V} \text {, }
$$

where $\mathrm{x}$ is the downrange distance from the muzzle to the stripper plate. This simplification assumes that the effect on flight time from velocity loss due to drag is negligible over this relatively short distance.

The displacement, s, of a body under uniform acceleration and zero initial radial velocity can be expressed as

$$
\mathrm{s}=1 / 2 \mathrm{at}^{2}
$$

Substituting and simplifying

$$
\begin{gathered}
\mathrm{S}=1 / 2 \mathrm{at}^{2}=1 / 2(\mathrm{~F} / \mathrm{m})(\mathrm{x} / \mathrm{V})^{2}=1 / 2\left(1 / 2 \rho \mathrm{V}^{2} \mathrm{~A} / \mathrm{m}\right)\left(\mathrm{x}^{2} / \mathrm{V}^{2}\right) \\
\mathrm{s}=\rho \mathrm{A} \mathrm{x}^{2} / 4 \mathrm{~m} .
\end{gathered}
$$

This shows that sabot displacement is independent of velocity for the simplified case. Of course for supersonic velocities, second order effects such as shock wave interactions will come into play. This was not an issue for the current case because both the full-scale and subscale firings were subsonic.

\subsection{Scale Invariance}

The question of how a 1/4-scale experiment can properly simulate a full-scale firing can be addressed with the following equations. The prior derivation showed that sabot displacement (s) is a function of mass (m), air density $(\rho)$, sabot area (A), and the distance to the stripper plate (x)

$$
\mathrm{s}=\rho \mathrm{Ax} \mathrm{x}^{2} / 4 \mathrm{~m}
$$

The following assumes that the sabot material (or at least the material density) is similar for the subscale and full-scale experiments (which was true for the sample case presented). If the launch hardware is scaled down by a ratio $\mathrm{R}$, which is the subscale diameter (subscript s) divided by the full-scale diameter (subscript $\mathrm{f}$ ), then the relative effects on mass, area, and distance obey the following proportionalities:

$$
\begin{aligned}
\mathrm{R} & =\mathrm{d}_{\mathrm{s}} / \mathrm{d}_{\mathrm{f}} \\
\mathrm{m}_{\mathrm{s}} & =\mathrm{m}_{\mathrm{f}} \mathrm{R}^{3} \\
\mathrm{~A}_{\mathrm{s}} & =\mathrm{A}_{\mathrm{f}} \mathrm{R}^{2} \\
\mathrm{x}_{\mathrm{s}} & =\mathrm{x}_{\mathrm{f}} \mathrm{R}
\end{aligned}
$$

Substituting and simplifying yields 


$$
\begin{gathered}
s_{s}=\rho A_{s} x_{s}^{2} / 4 m_{s}=\rho\left(A_{f} R^{2}\right)\left(x_{f} R\right)^{2} /\left(4 m_{f} R^{3}\right)=\rho A_{f} x_{f}^{2} R / 4 m_{f} \\
s_{s}=s_{f} R
\end{gathered}
$$

meaning that the subscale sabot displacement is equal to the full-scale displacement multiplied by the scaling ratio $\mathrm{R}$. In other words, the subscale displacement in calibers is the same as the full-scale displacement in calibers. This can be seen in Figs. 5, 6, and 9. These figures show fullscale and subscale sabot discard, but the pictures have been scaled so that the apparent bore diameter (as evidenced by the pusher disk) is the same for both. The sabot displacements appear to be virtually identical in both image sets.

\section{Conclusions}

It has been shown both experimentally and analytically that subscale, low-velocity flight experiments can be used for first order evaluation of sabot discard phenomena. The theoretical basis to explain this occurrence has been outlined. Experiments compared sabot discard patterns between 2-inch airgun launches and 8-inch powder gun firings, showing similar sabot discard patterns.

The subscale technique was successfully used to design a sabot configuration that would adequately divert the pusher disk so that it would not enter the spark range facility. The method incorporated a stripper pole to rigidly tie 1 of 4 sabot petals to the pusher disk, thereby pulling the pusher disk away from the range entrance opening so that it impacted on the stripper plate.

Low-cost, subscale components manufactured via 3-D printing allow quick and easy evaluation of sabot concepts. This can save significant cost and time in a sabot development project. This is particularly significant when the sabots are being used solely to expedite testing, and it is important to minimize the time and effort expended perfecting what is often a one-time-use sabot design. 


\section{References}

1. Fresconi F, Brown G, Celmins I, DeSpirito J, Ilg M, Maley J, Magnotti P, Scanlan A, Stout C, Vazquez E. Very affordable precision projectile technology and flight demonstrations. Aberdeen Proving Ground (MD): Army Research Laboratory (US); 2011 Report No.:

ARL-TR-5460. 
1 DEFENSE TECHNICAL

(PDF) INFORMATION CTR

DTIC OCA

2 DIRECTOR

(PDF) US ARMY RESEARCH LAB

RDRL CIO LL

IMAL HRA MAIL \& RECORDS MGMT

1 GOVT PRINTG OFC

(PDF) A MALHOTRA

1 DIR USARL

(PDF) RDRL WML E

I CELMINS 